\title{
SMaSh: A Streptavidin Mass Shift Assay for Rapidly Quantifying Target Occupancy by Irreversible Inhibitors
}

Matthew T. Labenski, Leslie A. Bateman, Lukas T. Voortman, Giulia Giammo, Susan Cantin, Lixin Qiao, Alan F. Corin*

${ }^{*}$ Corresponding Author:

Alan F. Corin

Bristol Myers Squibb

3401 Princeton Pike

Princeton, NJ 08648

afcorin@gmail.com 


\section{SUPPLEMENTARY FIGURES}

A

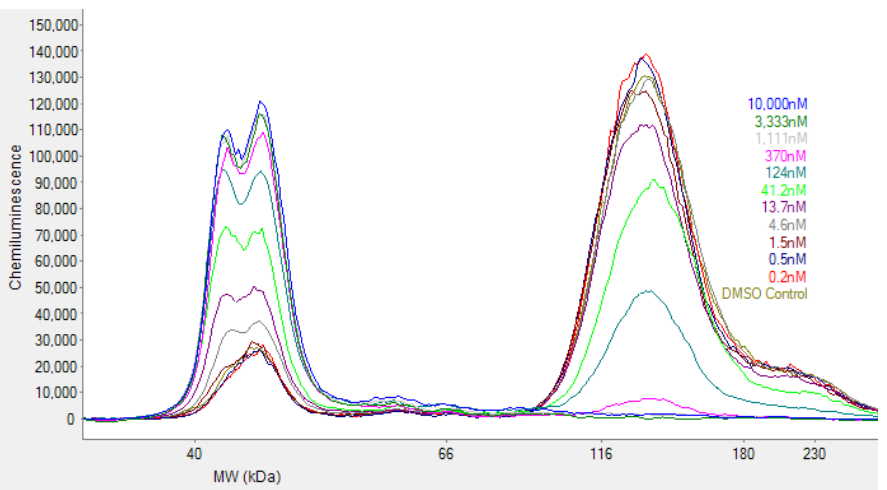

B

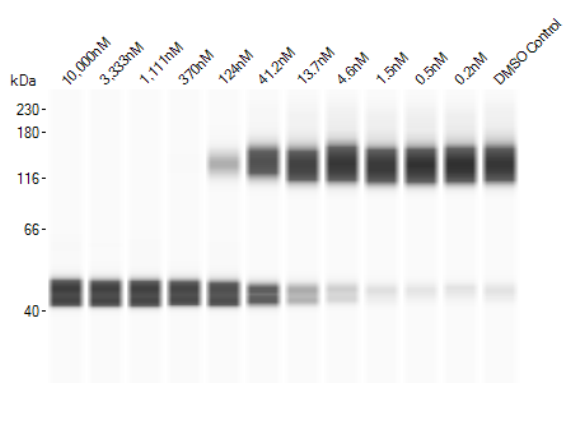

Figure S1. Related to Figure 1. Electropherogram of target engagement by $\mathbf{T C I}$ I2. Mouse spleen homogenates were pre-treated with $\mathrm{I}$, an ERK1/2 inhibitor, in a dose titration followed by $10 \mathrm{uM}$ probe P2 for 30 minutes at room temperature. (A) Electropherogram representation of dose titrations overlaid showing the inverse relationship between occupied and unoccupied ERK at 42 and $124 \mathrm{kDa}$, respectively. (B) Western blot view of (A). 12 and P2 structures provided in Figure 3.

A

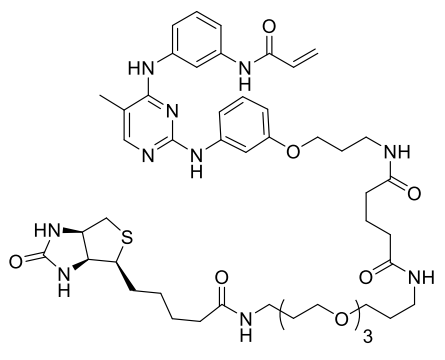

P3: $1 \mathrm{nM}$

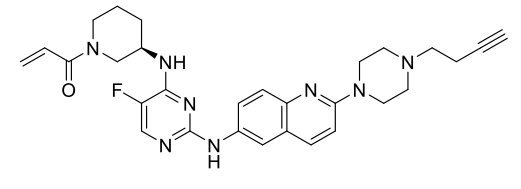

P4: $1.2 \mathrm{nM}$

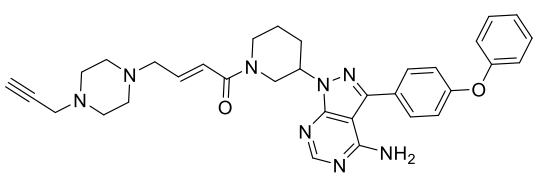

P5: $0.5 \mathrm{nM}$

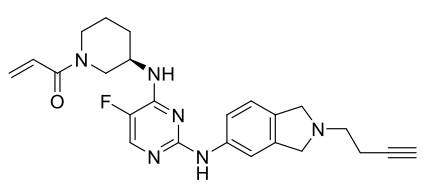

P6: $0.5 \mathrm{nM}$

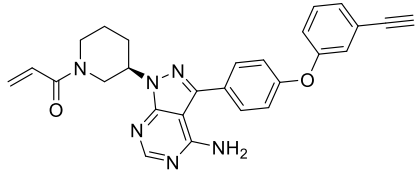

P7: n/a 

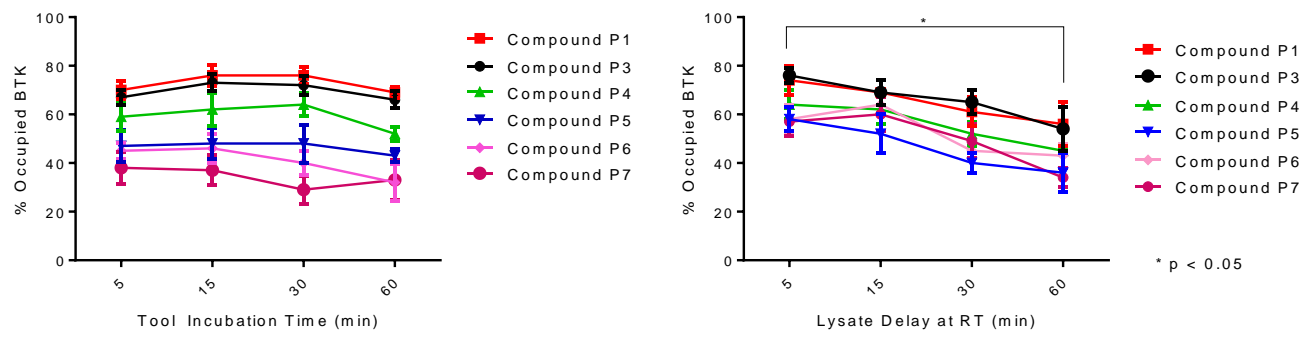

Figure S2. Related to Figure 2. BTK Probe Validation Studies. (A) Structures and IC50s for BTK probes P3-7. (B) Compounds P1, 3-7 were incubated in Ramos lysate for 5, 15, 30, 60 minutes at a final concentration of $10 \mathrm{uM}$. Occupancy was then determined using the SMaSh Assay. No change in occupancy was noted with incubation time, although each probe occupied different amounts of BTK. No statistically significant change in occupancy was observed. (C) Ramos lysates were left at room temperature for 5, 15, 30 and 60 minutes prior to the addition of compounds P1, 3-7 at a final concentration of $10 \mathrm{uM}$. Decrease in occupancy with time, suggests destabilization of BTK. All compounds, excluding P6, showed a statistically significant decrease in occupancy at 60 minutes $(p<0.05)$.

A

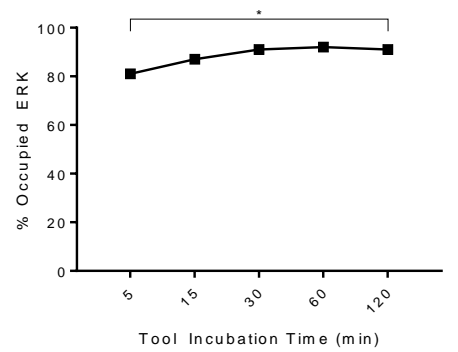

B

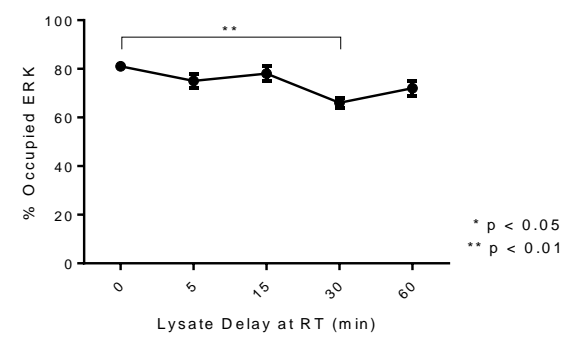


Figure S3. Related to Figure 3. ERK Probe Validation Studies. (A) Compound P2 was incubated in A375 lysate for $5,15,30,60$ and 120 minutes at a final concentration of $10 \mathrm{uM}$. Occupancy was then determined using the SMaSh Assay. No change in occupancy was noted with incubation time, with maximum occupancy observed within the first 30 minutes of incubation (B) A375 lysates were left at room temperature for $5,15,30$ and 60 minutes prior to the addition of P2 at a final concentration of $10 \mathrm{uM}$. A slight decrease in occupancy with time was observed, suggesting a destabilization of ERK over time.

Figure S4
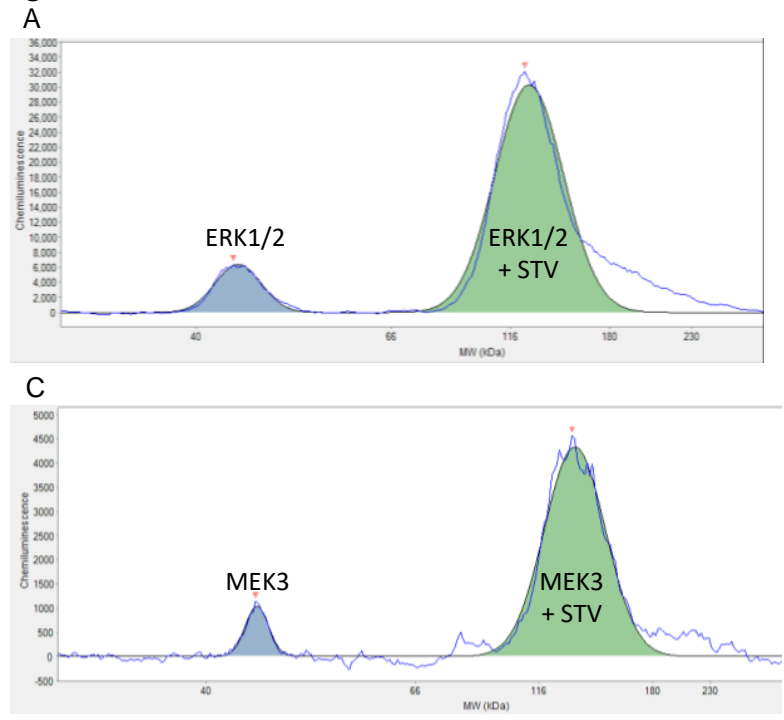

B

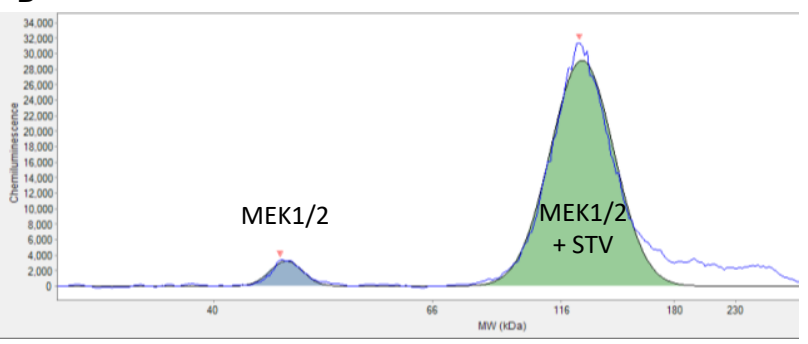

D

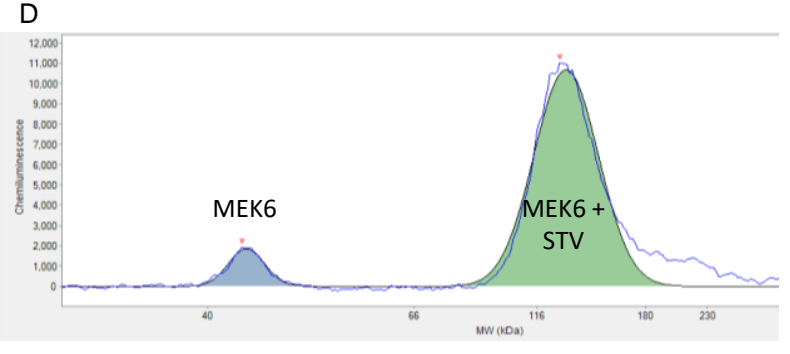

Figure S4. Related to Figure 3. Electropherogram of target and off-target engagement. A375 lysate treated with $10 \mathrm{uM}$ P2 for 30 minutes at room temperature. (A) Unmodified ERK1/2 (blue peak) at $42 \mathrm{kDa}$ and modified ERK1/2 (green peak) at $124 \mathrm{kDa}$ (ERK1/2 + P2 + STV). Area under the curves used for the calculation of occupancy. Similarly for (B) MEK1/2 at $49 \mathrm{kDa}$, (C) MEK3 at $45 \mathrm{kDa}$, (D) MEK6 at $43 \mathrm{kDa}$. 


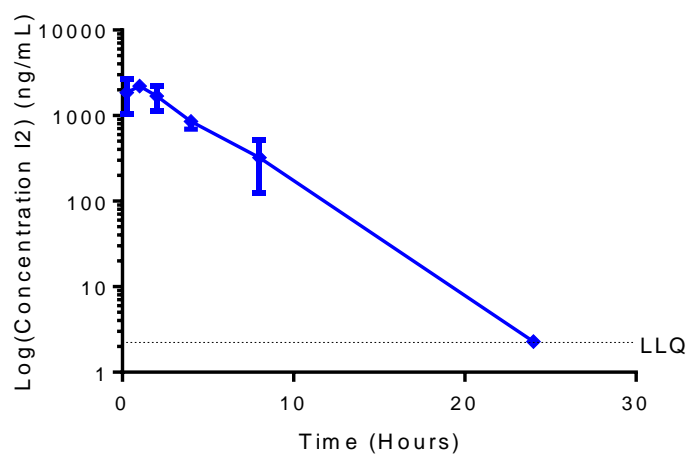

Figure S5. Related to Figure 5. Pharmacokinetics of I2. Decrease of 12 over time in plasma of mice treated with $100 \mathrm{mg} / \mathrm{kg}$ of $\mathrm{I} 2$ by oral gavage. Levels steadily decreased over time and were undetectable by 24 hours, post-dose. 


\section{Additional Supporting Materials}

\section{Scheme 1: Synthesis of Biotin Azide}

Preparation of methyl 4-hydroxypicolinate (1)

Preparation of methyl 4-(2-(tert-butoxycarbonylamino)ethoxy)picolinate (2)

Preparation of tert-butyl 2-(2-(hydroxymethyl)pyridin-4-yloxy)ethylcarbamate (3)

Preparation of (4-(2-(tert-butoxycarbonylamino)ethoxy)pyridin-2-yl)methyl methane sulfonate (4)

Preparation of tert-butyl 2-(2-(azidomethyl)pyridin-4-yloxy)ethylcarbamate

Preparation of N1-(2-((2-(azidomethyl)pyridin-4-yl)oxy)ethyl)-N5-(15-oxo-19-((3aS,4S,6aR)-2oxohexahydro-1H-thieno[3,4-d]imidazol-4-yl)-4,7,10-trioxa-14-azanonadecyl)glutaramide

Quantitation of Compound P2 in Plasma

Scheme 1: Synthesis of a biotinylated azide for use in biotinylating alkyne derivatized probe molecules:

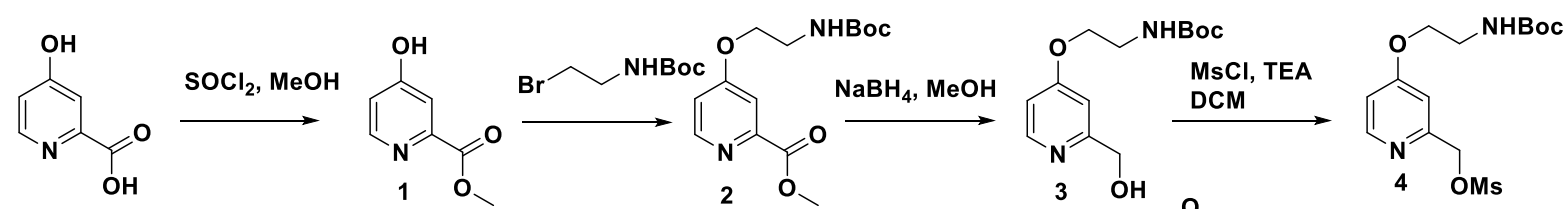

4-hydroxypicolinic acid
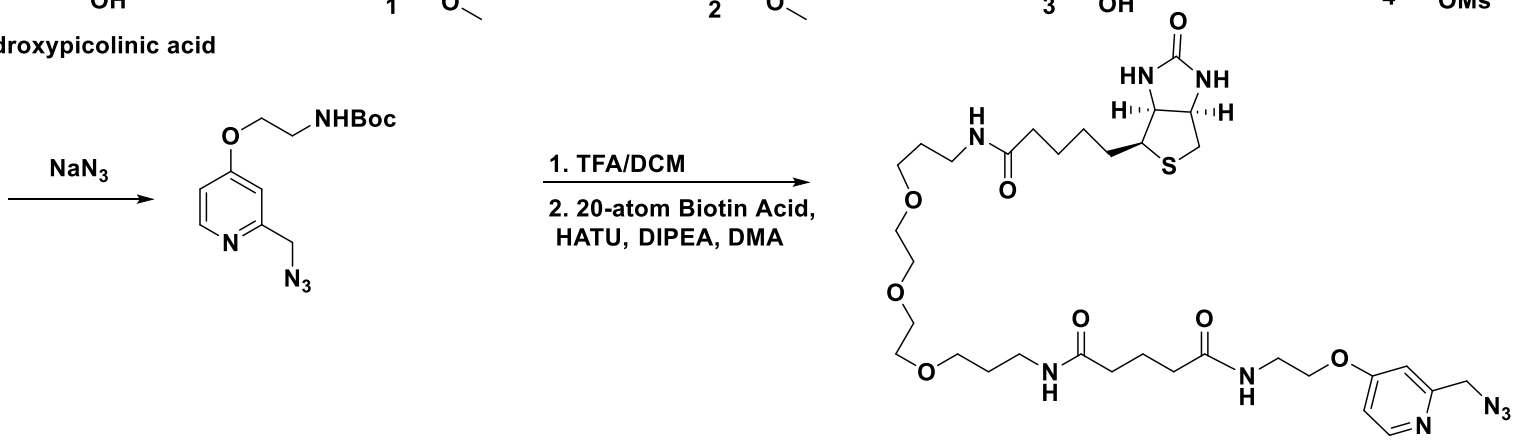

Preparation of methyl 4-hydroxypicolinate (1): To a stirred solution of 4-hydroxypyridine-2-carboxylic acid $(50 \mathrm{~g}, 86.26 \mathrm{mmol})$ in methanol $(300 \mathrm{~mL})$ was added $\mathrm{SOCl}_{2}(150 \mathrm{~mL})$ at $0^{\circ} \mathrm{C}$, and reaction mixture stirred for 12 hours at reflux. The reaction mixture was concentrated under reduced pressure. The residue obtained was diluted with hexane and filtered. The crude product was washed with hexane to yield methyl 4-hydroxypicolinate as an off-white solid ( $40 \mathrm{~g}, 72 \%$ yield).

1HNMR (DMSO-d, $400 \mathrm{MHz}) \delta 8.45(\mathrm{~d}, 1 \mathrm{H}, \mathrm{J}=6.4 \mathrm{~Hz}), 7.60(\mathrm{br} \mathrm{d}, 1 \mathrm{H}, \mathrm{J}=6.4 \mathrm{~Hz}), 7.26(\mathrm{br} \mathrm{s}, 1 \mathrm{H}), 3.94$ $(\mathrm{s}, 3 \mathrm{H})$.

Preparation of methyl 4-(2-(tert-butoxycarbonylamino)ethoxy)picolinate (2): To a solution of methyl 4hydroxypicolinate $(50 \mathrm{~g}, 326.79 \mathrm{mmol})$ in dimethylformamide $(300 \mathrm{~mL})$, was added cesium carbonate (318.6 g, $980.39 \mathrm{mmol})$ and tert-butyl N-(2-bromoethyl) carbamate $(105.2 \mathrm{~g}, 653.6 \mathrm{mmol})$. The reaction mixture was stirred at RT for 12 hours. The reaction mixture was diluted with ethyl acetate and washed with water, then saturated brine solution. The organic layer was dried over anhydrous sodium sulfate and 
concentrated under reduced pressure. The crude product was purified by column chromatography to give methyl 4-(2-(tert-butoxycarbonylamino) ethoxy) picolinate as an off-white solid. (30 g, 31\% yield).

$1 \mathrm{HNMR}\left(\mathrm{CDCl}_{3}, 400 \mathrm{MHz}\right) \delta 8.58(\mathrm{br} \mathrm{s}, 1 \mathrm{H}), 7.67$ (br s, 1H, 7.00 (s, 1H), 4.92 (br s, 1H), 4.16 (br s, 2H), $4.01(\mathrm{~s}, 3 \mathrm{H}), 3.57$ (br s, 2H), $1.45(\mathrm{~s}, 9 \mathrm{H})$.

Preparation of tert-butyl 2-(2-(hydroxymethyl)pyridin-4-yloxy)ethylcarbamate (3): To a solution of methyl 4-(2-(tert-butoxycarbonylamino) ethoxy) picolinate (2) $(30.0 \mathrm{~g}, 101.3 \mathrm{mmol})$ in tetrahydrofuran $(900.0 \mathrm{~mL})$, was added sodium borohydride hydride $(3.75 \mathrm{~g}, 101.3 \mathrm{mmol})$ at $0^{\circ} \mathrm{C}$. After stirring the reaction mixture for 30 minutes at room temperature, methanol $(240 \mathrm{~mL})$ was added and stirring was continued for 4 hours at room temperature. Methanol was evaporated; the residue was quenched with saturated ammonium chloride solution, extracted with ethyl acetate and washed with brine solution. The organic layer was dried over anhydrous sodium sulfate and was concentrated under reduced pressure to yield tert-butyl 2-(2(hydroxymethyl) pyridin-4-yloxy) ethylcarbamate (3) as an off-white solid (15 g, 55\% yield).

1HNMR (DMSO-d $\left.d_{6}, 400 \mathrm{MHz}\right) \delta 8.25(\mathrm{~d}, 1 \mathrm{H}, \mathrm{J}=5.6 \mathrm{~Hz}$ ), 6.97 (br s, 2H), 6.79 (br d, 1H, J = 2.4 Hz), 4.68 (br s, $1 \mathrm{H}), 5.32(\mathrm{brt}, 1 \mathrm{H}, \mathrm{J}=5.2 \mathrm{~Hz}), 4.48(\mathrm{~d}, 2 \mathrm{H}, \mathrm{J}=4.8 \mathrm{~Hz}), 4.02(\mathrm{t}, 2 \mathrm{H}, \mathrm{J}=5.6 \mathrm{~Hz}), 3.29(\mathrm{brt}, 3 \mathrm{H}, \mathrm{J}=$ $\left.4.8 \mathrm{~Hz}, \mathrm{CH}_{2}+\mathrm{OH}\right), 1.36(\mathrm{~s}, 9 \mathrm{H})$.

Preparation of (4-(2-(tert-butoxycarbonylamino)ethoxy)pyridin-2-yl)methyl methane sulfonate (4): To a solution of tert-butyl 2-(2-(hydroxymethyl)pyridin-4-yloxy)ethylcarbamate (3) $(11 \mathrm{~g}, 41 \mathrm{mmol})$ in dichloromethane $(110 \mathrm{~mL})$, was added triethylamine $(12.44 \mathrm{~g}, 123.04 \mathrm{mmol})$ and methanesulfonyl chloride $(5.87 \mathrm{~g}, 51.26 \mathrm{mmol})$ at $0^{\circ} \mathrm{C}$. The reaction mixture was stirred at room temperature for 2 hours. The reaction mixture was diluted with dichloromethane, washed with water, and brine solution. The organic layer was dried over anhydrous sodium sulfate and concentrated under reduced pressure to obtain (4-(2-(tert-butoxycarbonylamino) ethoxy) pyridin-2-yl) methyl methane sulfonate as a brown oil (4) (12 g, 77\% yield). The crude material was used directly in the following step.

Preparation of tert-butyl 2-(2-(azidomethyl)pyridin-4-yloxy)ethylcarbamate: To a solution of (4-(2-(tertbutoxycarbonylamino)ethoxy)pyridin-2-yl)methyl methane sulfonate (4) $(12 \mathrm{~g}, 34.68 \mathrm{mmol})$ in dimethylacetamide $(60 \mathrm{~mL})$, was added sodium azide $(6.7 \mathrm{~g}, 103.07 \mathrm{mmol})$ slowly at $0{ }^{\circ} \mathrm{C}$. The reaction mixture was stirred at room temperature for 2 hours. The reaction mixture was diluted with dichloromethane, washed with water, and wash with brine solution. The organic layer was dried over anhydrous sodium sulfate and concentrated under reduced pressure. The crude obtained was purified by column chromatography to obtain tert-butyl 2-(2-(azidomethyl) pyridin-4-yloxy) ethylcarbamate as a brown semi-solid (4 g, 40\% yield).

1HNMR (DMSO-d $\left.d_{6}, 400 \mathrm{MHz}\right) \delta 8.37(\mathrm{~d}, 1 \mathrm{H}, \mathrm{J}=5.6 \mathrm{~Hz}), 6.98(\mathrm{br} \mathrm{s}, 2 \mathrm{H}), 6.90(\mathrm{~d}, 1 \mathrm{H}, \mathrm{J}=3.6 \mathrm{~Hz}), 4.41(\mathrm{~s}$, $2 \mathrm{H}), 4.07(\mathrm{t}, 2 \mathrm{H}, \mathrm{J}=5.26 \mathrm{~Hz}), 3.30(\mathrm{~m}, 3 \mathrm{H}), 1.36(\mathrm{~s}, 9 \mathrm{H})$.

LC-MS: m/z $294.1(E S+, M+H)$.

Preparation of N1-(2-((2-(azidomethyl)pyridin-4-yl)oxy)ethyl)-N5-(15-oxo-19-((3aS,4S,6aR)-2oxohexahydro-1H-thieno[3,4-d]imidazol-4-yl)-4,7,10-trioxa-14-azanonadecyl)glutaramide: To a $100 \mathrm{~mL}$ round-bottomed flask was added tert-butyl (2-((2-(azidomethyl)pyridin-4-yl)oxy)ethyl)carbamate (2.13 g, $7.26 \mathrm{mmol})$ in dichloromethane $(20 \mathrm{~mL})$ to give a colorless solution. TFA $(6.5 \mathrm{ml}, 84 \mathrm{mmol})$ was added slowly, the resulting mixture was stirred at room temperature for $30 \mathrm{~min}$. The solution was concentrated, and co-evaporated with acetonitrile $3 \times 20 \mathrm{~mL}$.

In a $100 \mathrm{~mL}$ round-bottomed flask was added $\mathrm{N}$-ethyl-N-isopropylpropan-2-amine 5,21-dioxo-25((3aS,4S,6aR)-2-oxohexahydro-1H-thieno[3,4-d]imidazol-4-yl)-10,13,16-trioxa-6,20-diazapentacosan-1oate $(4.0 \mathrm{~g}, 5.6 \mathrm{mmol})$ in dimethylacetamide $(20 \mathrm{~mL})$ and DIPEA $(12 \mathrm{~mL}, 68 \mathrm{mmol})$ to give a white suspension. HATU $(2.6 \mathrm{~g}, 6.8 \mathrm{mmol})$ was added to form a clear yellow solution, followed by de-Boc intermediate solution obtained above. The resulting mixture was stirred at room temperature overnight. 
After concentration, the mixture was purified by prep-HPLC using formic acid as a modifier. The final product was lyophilized to a white semi-solid $(2.0 \mathrm{~g}, 47 \%)$, and was extremely hygroscopic.

1HNMR (CD $\left.{ }_{3} \mathrm{OD}, 400 \mathrm{MHz}\right) \delta 8.56(\mathrm{~d}, 1 \mathrm{H}, \mathrm{J}=6.8 \mathrm{~Hz}), 7.51(\mathrm{~d}, 1 \mathrm{H}, \mathrm{J}=2.8 \mathrm{~Hz}), 7.45(\mathrm{dd}, 1 \mathrm{H}, \mathrm{J}=2.4,7.2$ $\mathrm{Hz}$ ), $4.48(\mathrm{AB} \mathrm{q}, 1 \mathrm{H}, \mathrm{J}=4.4,7.6 \mathrm{~Hz}), 4.41(\mathrm{t}, 2 \mathrm{H}, \mathrm{J}=5.2 \mathrm{~Hz}), 4.29(\mathrm{AB} \mathrm{q}, 1 \mathrm{H}, \mathrm{J}=4.4,7.6 \mathrm{~Hz}), 3.61 \sim 3.67$ $(\mathrm{m}, 6 \mathrm{H}), 3.55 \sim 3.59(\mathrm{~m}, 4 \mathrm{H}), 3.50(\mathrm{dt}, 4 \mathrm{H}, \mathrm{J}=3.2,6.0 \mathrm{~Hz}), 3.17 \sim 3.26(\mathrm{~m}, 5 \mathrm{H}), 2.91(\mathrm{dd}, 1 \mathrm{H}, \mathrm{J}=3.2,12.8$ $\mathrm{Hz}), 2.68(\mathrm{~d}, 1 \mathrm{H}, \mathrm{J}=12.4 \mathrm{~Hz}), 2.16 \sim 2.26(\mathrm{~m}, 6 \mathrm{H}), 1.85(\mathrm{~m}, 2 \mathrm{H}), 1.55 \sim 1.78(\mathrm{~m}, 8 \mathrm{H}), 1.42(\mathrm{~m}, 2 \mathrm{H})$.

LC-MS: m/z $736.3(E S+, M+H)$.

\section{Quantitation of Compound 12 in Plasma:}

The plasma samples were analyzed for unchanged $\mathbf{2}$ using HPLC/tandem mass spectrometry. The internal standard $(100 \mathrm{ng} / \mathrm{mL}$ solution in acetonitrile) was added to $50 \mu \mathrm{L}$ of the plasma sample, mixed briefly and then filtered through an Orochem protein precipitation plate into a clean 96 well plate. To the resulting supernatant $(\sim 200 \mu \mathrm{L})$ an aliquot of $\sim 100 \mu \mathrm{L}$ of water was added and vortexed briefly. A $5 \mu \mathrm{L}$ sample was injected on a system that consisted of Shimadzu HPLC pumps; model LC-20AD XR and a CMB-20A system controller, (Columbia, MD) and LEAP autosampler (CTC Analytics; LEAP Technologies Inc., Carrboro, NC) and was attached to a API 6500+ QTRAP mass spectrometer (AB Sciex LLC, Framingham, MA) equipped with an atmospheric-pressure chemical ionization interface.

The internal standard and $\mathbf{I} 2$ were separated chromatographically using an ACE ${ }^{\circledR}$ Excel $3 \mathrm{C}_{8} 3.5(30 \times 2.1$ $\mathrm{mm}$ ) analytical column at ambient temperature. The separation was carried out using $0.1 \%$ formic acid in water, Solvent $A$, and acetonitrile with $0.1 \%$ formic acid, Solvent B, as mobile phase and at a flow rate of $0.850 \mu \mathrm{L} / \mathrm{min}$. The gradient system used was as follows: $95 \%$ solvent $A$ from 0 to $0.15 \mathrm{~min}$, changed from 95 to $20 \%$ solvent $A$ from 0.15 to $2.5 \mathrm{~min}$. At $2.51 \mathrm{~min}$, changed from $20 \%$ solvent $A$ to $5 \%$ solvent $A$, kept at $5 \% \mathrm{~A}$ for $0.6 \mathrm{~min}$, then at $3.11 \mathrm{~min}$ changed from $5 \% \mathrm{~A}$ to $95 \% \mathrm{~A}$. The column was then allowed to equilibrate at $95 \% \mathrm{~A}$ for the next $0.5 \mathrm{~min}$ before the next sample was injected.

Compounds were detected in a positive ion mode and analyzed by multiple reaction monitoring (MRM). The following MRM $\mathrm{m} / \mathrm{z}$ transitions were monitored for I2: precursor and product ion $\mathrm{m} / \mathrm{z}$ of $459.3 \rightarrow 427.2$, respectively with a declustering potential (DP) of $110 \mathrm{~V}$, a collision cell exit potential (CXP) of $10 \mathrm{~V}$, a collision energy (CE) of $35 \mathrm{~V}$. For the internal standard the following MRM m/z transitions were monitored: precursor and product ion $\mathrm{m} / \mathrm{z}$ of $272.0 \rightarrow 156.0$, respectively, a DP of $70 \mathrm{~V}$, a CXP of $10 \mathrm{~V}$, and CE of 30 V. The retention times of $\mathbf{I} 2$ and the internal standard were 1.58 and $1.23 \mathrm{~min}$, respectively.

Data collection and integration were done on Analyst (version 1.6.3). The ratio of peak area responses of drug relative to internal standard was used to construct a standard curve using a linear least square regression with a $1 / x$ weighting. The dynamic range of the assay was 1 to $5000 \mathrm{ng} / \mathrm{mL}$. 